\title{
Characterization of Black Ginseng Extract with Acetyl- and Butyrylcholin- esterase Inhibitory and Antioxidant Activities
}

\author{
Beom Sik Yun ${ }^{1}$, Mi Ra Lee ${ }^{1}$ Chang Jin Oh ${ }^{1}$, Jeong Hee Cho ${ }^{1}$, Chun Yan Wang ${ }^{2}$, Li Juan Gu ${ }^{2}$, \\ Eun Kyung $\mathrm{Mo}^{2}$, and Chang Keun Sung ${ }^{{ }^{*}}$ \\ ${ }^{1}$ Department of Food Science and Technology, Chungnam National University, Daejeon 305-764, Korea \\ ${ }^{2}$ Daeduck Bio Research Institute, Daejeon 305-764, Korea
}

Black ginseng and white ginseng were extracted with $80 \%$ ethanol and evaluated for relative ginsenoside composition, acetylcholinesterase $(\mathrm{AChE})$ and butyrylcholinesterase $(\mathrm{BChE})$ inhibitory activities, and antioxidant properties. As analyzed by HPLC, black ginseng contained a greater proportion of ginsenoside $\mathrm{Rg}_{3}$ compared to white ginseng. White ginseng was characterized by undetectable ginsenoside $\mathrm{Rg}_{3}$ but it contained more total ginsenosides than black ginseng. Black ginseng extract exhibited higher $(p<0.05)$ free radical-scavenging activity, as well as higher antioxidant activities than white ginseng against 2,2-diphenyl-1-picryl-hydrazyl, superoxide dismutase, and xanthine oxidase, despite the fact that the total saponin content was higher in white ginseng than black ginseng. In addition, the black ginseng extract displayed greater AChE and $\mathrm{BChE}$ inhibitory activities. These results suggest that black ginseng has stronger effects on anti-oxidation and AChE and $\mathrm{BChE}$ inhibition than white ginseng.

Keywords: Black ginseng, Acetylcholinesterase, Butyrylcholinesterase, Antioxidation, Acetylcholine

\section{INTRODUCTION}

Ginseng, one of the most popular herbs in the world, is considered a tonic or adaptogen that enhances physical performance, promotes vitality, and increases resistance to stress and aging [1]. In Asia, a variety of commercial ginseng products are sold, including white, red, and black ginseng. White ginseng is produced as a result of dehydration by the sun, whereas red ginseng is produced by steaming at $95-100^{\circ} \mathrm{C}$ for $2-3 \mathrm{~h}$. Black ginseng is produced from white ginseng through nine cycles of steam treatment, at which point it becomes black in color [2].

The non-saponin components of Korean red ginseng exhibit the scavenging effects on free radicals that are related to the aging of cells. Moreover, phenolic com- pounds and maltol of ginseng have been reported to play an important role in inhibiting aging. Maltol is a substance produced by the pyrolysis of hexose when steamed at high temperatures during the manufacturing process of red ginseng [3]. Besides maltol, red ginseng contains antioxidant components, including salicylic acid, ferulic acid [4], gentisic acid [5], caffeic acid, and vanillic acid. Such phenolic compounds show antioxidant effects in tissues of animals with extreme oxidative injury. A comparison of the phenolic compounds found in Korean ginseng and American ginseng has indicated that certain polyphenol components exist only in Korean ginseng [6].

Acetylcholine $(\mathrm{ACh})$ is a key neurotransmitter in (c) This is an Open Access article distributed under the terms of the Creative Commons Attribution Non-Commercial License (http://creativecommons.org/licenses/by-nc/3.0/) which permits unrestricted non-commercial use, distribution, and reproduction in any medium, provided the original work is properly cited.
Received 17 Aug. 2010, Revised 9 Sep. 2010, Accepted 29 Sep. 2010

*Corresponding author

E-mail: kchsung@cnu.ac.kr

Tel: +82-42-821-6722, Fax: +82-42-822-2287 
learning and memory and its activity is terminated by its hydrolysis into acetate and choline by acetylcholinesterase (AChE) [7]. Two forms of cholinesterase coexist ubiquitously throughout the body, AChE and butyrylcholinesterase (BChE), and although highly homologous $(>65 \%)$, they are products of different genes on chromosomes 7 and 3, respectively, in humans [8].

In this study, we investigated black ginseng for possible $\mathrm{AChE}$ and $\mathrm{BChE}$ inhibitory activities, which may explain the effect it has on mental performance. Moreover, the objectives of this study were to compare the antioxidant properties and contents of potential antioxidants between black and white ginseng extracts.

\section{MATERIALS AND METHODS}

\section{Preparation of ginseng extracts}

White ginseng was made from 4-year-old ginseng purchased from a local ginseng center (Geumsan, Korea). Black ginseng was manufactured via nine cycles of repeated steaming of white ginseng at $98^{\circ} \mathrm{C}$ for $3 \mathrm{~h}$ and drying at $60^{\circ} \mathrm{C}$ for $18 \mathrm{~h}$. To prepare ginseng extracts, ginseng was crushed into a powder and ultrasonicated three times in 10 volumes of $80 \%$ ethanol at $50^{\circ} \mathrm{C}$ for $1 \mathrm{~h}$, then filtered and lyophilized.

\section{Sample preparation for HPLC analysis}

Based on the method of Shi et al. [9] with modification, 1-g dried ginseng powder was extracted three times with $50 \mathrm{~mL}$ of $80 \%$ ethanol aqueous solution at $50^{\circ} \mathrm{C}$ by ultrasonication $(60 \mathrm{~Hz}$, heat power $600 \mathrm{~W}$; Powersonic 510, Hwashin, Korea) for $60 \mathrm{~min}$. After filtration using filter paper (Advantec, Dublin, CA, USA), the solvent was removed using an evaporator (EYELA N-N series; Rikakikai Co., Tokyo, Japan), and the residue was dissolved in $20 \mathrm{~mL}$ of distilled water. The solution was transferred to a separatory funnel containing the same volume of ethyl ether. Lipid components in the sample were removed by extracting with ethyl ether three times. The sample was further extracted with $20 \mathrm{~mL}$ of watersaturated butanol and concentrated in vacuo. The samples were then dissolved in $10 \mathrm{~mL}$ of $80 \%$ methanol and filtered through a $0.45-\mu \mathrm{m}$ membrane filter.

\section{Saponin analysis}

Saponin levels were quantified by HPLC analysis (SPD 20A; Shimadzu, Kyoto, Japan) using an ACE 5 $\mathrm{C}_{18}$ column $(250 \pm 0.4 \mathrm{~mm}, 5 \mu \mathrm{m})$ and UV detector $(203$ $\mathrm{nm})$. The mobile phase was a gradient of water and acetonitrile. To elute saponin, the acetonitrile concentration was adjusted as follows: $0-30 \mathrm{~min}, 20 \%$; $30-60 \mathrm{~min}$, 20-45\%; 60-78 min, 45-75\%; 78-80 min, 75-80\%; $80-100 \mathrm{~min}, 80-100 \%$ [9]. After injecting $10 \mu \mathrm{L}$ of sample, the mobile-phase flow rate was adjusted to 1 $\mathrm{mL} / \mathrm{min}$. As controls, ginsenoside standards $\left(\mathrm{Rg}_{1}, \mathrm{Re}\right.$, $\mathrm{Rh}_{1}, \mathrm{Rb}_{1}, \mathrm{Rc}, \mathrm{Rb} \mathrm{b}_{2}, \mathrm{Rd}, 20(\mathrm{R})-\mathrm{Rg}_{3}$, and $\left.20(\mathrm{~S})-\mathrm{Rg}_{3}\right)$ of $>98 \%$ purity were purchased from Hongjiu Biotech Co. (Jilin, China).

\section{In vitro cholinesterase inhibitory activity assay}

The inhibitory activities against cholinesterases (ChEs) were measured using the spectrophotometric method developed by Ellman et al. [10]. ACh and butyrylcholine were used as the substrates to assay the inhibition of $\mathrm{AChE}$ and $\mathrm{BChE}$, respectively. The assay mixture consisted of $340 \mu \mathrm{L}$ of $0.1 \mathrm{M}$ sodium phosphate buffer ( $\mathrm{pH} 8.0$ ), $40 \mu \mathrm{L}$ of $2 \mathrm{mM} 5,5^{\prime}$-dithiobis (2-nitrobenzoic acid) (DTNB), $40 \mu \mathrm{L}$ of the sample, and $460 \mu \mathrm{L}$ of either AChE or BChE $(0.22 \mathrm{U} / \mathrm{mL}$ prepared in $50 \mathrm{mM}$ Tris buffer, $\mathrm{pH} 8.0$, containing $0.1 \%$ bovine serum albu$\mathrm{min}$ ). After $10 \mathrm{~min}$, the reactions were initiated with the addition of $10 \mu \mathrm{L}$ of either $3.75 \mathrm{mM}$ acetylthiocholine iodide (ATCI) or $40 \mu \mathrm{L}$ of $3.75 \mathrm{mM}$ butyrylthiocholine chloride (BTCC) to the solution. The hydrolysis of ATCI or BTCC was monitored by following the formation of the yellow 5-thio-2-nitrobenzoate anion at $410 \mathrm{~nm}$ for 2 min, which resulted from the reaction of DTNB with thiocholine that was released by the enzymatic hydrolysis of either ATCI or BTCC, respectively. The percent inhibition was calculated from $\left[\left(\mathrm{A}_{0}-\mathrm{A}_{1}\right) / \mathrm{A}_{0}\right]^{\prime} 100$, where $\mathrm{A}_{0}$ is the change in absorbance of the control and $\mathrm{A}_{1}$ is the change in absorbance in the presence of the test compound. The $\mathrm{ChE}$ inhibitory activity of each sample was expressed in terms of the $\mathrm{IC}_{50}$ value $(\mathrm{mg} / \mathrm{mL}$ or $\mathrm{nM} /$ $\mathrm{mL}$ required to inhibit the hydrolysis of the substrate, ATCI or BTCC, by $50 \%$ )

\section{Determination of total polyphenol contents}

The method of Folin-Denis was used for measuring total polyphenol contents [11]. Samples of $0.2 \mathrm{~mL}$ of each extract $(10 \mathrm{mg} / \mathrm{mL})$ and $0.2 \mathrm{~mL}$ of Folin-Ciocalteu reagent was mixed with $1.8 \mathrm{~mL}$ of distilled water. After 3 min of incubation, $0.4 \mathrm{~mL}$ of sodium carbonate saturated solution and $1.4 \mathrm{~mL}$ of distilled water was added and the mixture was incubated for $1 \mathrm{~h}$. The absorbance at $725 \mathrm{~nm}$ was measured and converted to phenolic contents according to a calibration curve of tannic acid. The concentration of total phenolic compounds in the extracts was calculated using the following linear equation based on the calibration curve $(\mathrm{r}=0.998): y=0.002 x-0.06$, 
where $y$ is the absorbance and $x$ is the total phenolic contents in micrograms tannic acid equivalent per milliliter extract.

\section{Scavenging activity on the 2,2-diphenyl-1-picryl- hydrazyl radicals}

The free radical scavenging activity of ethanol extracts and their solvents were measured by the 2,2-diphenyl-1-picryl-hydrazyl (DPPH) method proposed by Blois [12]. Briefly, a $0.4 \mathrm{mM}$ solution of DPPH was prepared in ethanol and $0.8 \mathrm{~mL}$ of this solution was added to $0.2 \mathrm{~mL}$ of sample at different concentrations. After 10 min, the absorbance was measured at $540 \mathrm{~nm}$ and compared to the concentrations of ascorbic acid as a positive control. The $\mathrm{SC}_{50}$ (scavenging activity) is the concentration of sample needed to reduce the DPPH concentration by $50 \%$ compared to that of the control. The DPPH radical-scavenging activity was calculated according to the equation: DPPH scavenging activity $(\%)=\left[\left(\mathrm{A}_{0}-\mathrm{A}_{1}\right) /\right.$ $\left.A_{0}\right] \times 100$, where $A_{0}$ is the absorbance of the control and $A_{1}$ is the absorbance in the presence of the test compound.

\section{Superoxide dismutase activity}

Superoxide dismutase (SOD) activity was measured by the inhibition of pyrogallol autoxidation at $420 \mathrm{~nm}$ for 2 min using a kinetic assay according to Marklund and Marklund [13]. The enzyme activity was expressed relative to that of the control. The assay mixture consisted of $1.8 \mathrm{~mL}$ of $50 \mathrm{mM}$ Tris- $\mathrm{HCl}$ buffer $(\mathrm{pH} 8.5)$ containing $10 \mathrm{mM}$ EDTA plus $0.1 \mathrm{~mL}$ of the sample. The measurement started with the addition of $0.1 \mathrm{~mL}$ of $7.2 \mathrm{mM}$ pyrogallol to the solution. The SOD-like activity was calculated according to the equation: SOD-like activity $(\%)=\left[\left(\mathrm{A}_{0}-\mathrm{A}_{1}\right) / \mathrm{A}_{0}\right] \times 100$, where $\mathrm{A}_{0}$ is the absorbance of the control and $\mathrm{A}_{1}$ is the absorbance in the presence of the test compound.

\section{Xanthine oxidase inhibition}

Xanthine oxidase (XO) inhibition activity was measured by the inhibition of XO at $295 \mathrm{~nm}$ for $3 \mathrm{~min}$ according to the method of Stirpe and Corte [14]. The assay mixture consisted of $250 \mu \mathrm{L}$ of $50 \mathrm{mM}$ potassium phosphate buffer (pH 7.5), $300 \mu \mathrm{L}$ of $0.15 \mathrm{mM}$ xanthine solution (prepared in buffer with a minimum $1 \mathrm{~N}$ $\mathrm{NaOH}$ ), and $150 \mu \mathrm{L}$ of the sample. The measurement started with the addition of $300 \mu \mathrm{L}$ of XO $(0.2 \mathrm{U} / \mathrm{mL})$ in cold buffer. The inhibitory activity was represented as $\mathrm{IC}_{50}$, which is the concentration of sample required to reduce the $\mathrm{XO}$ concentration by $50 \%$ compared to that of the control. The XO inhibition activity was calculated according to the following equation: $\mathrm{XO}$ inhibition activity $(\%)=\left[\left(\mathrm{A}_{0}-\mathrm{A}_{1}\right) / \mathrm{A}_{0}\right] \times 100$, where $\mathrm{A}_{0}$ is the change in absorbance of the control and $A_{1}$ is the change in absorbance in the presence of the test compound.

\section{Statistical analysis}

All data were analyzed using the SPSS ver. 17.0 (SPSS Inc., Chicago, IL, USA). Differences between groups were analyzed using ANOVA and Duncan's multiple range test. A $p$-value of $<0.05$ was considered to be statistically significant.

\section{RESULTS AND DISCUSSION}

\section{Saponin analysis}

The 20(S)-ginsenoside $\mathrm{Rg}_{3}$ might provide neuroprotection against cerebral ischemia-induced injury in the rat brain through reducing lipid peroxides, scavenging free radicals, and improving energy metabolism [15]. 20(S)-ginsenoside $\mathrm{Rg}_{3}$ and $\mathrm{Rg}_{5} / \mathrm{Rk}_{1}$ significantly reversed the memory dysfunction induced by ethanol or scopolamine (SCOP) and their neuroprotective actions against excitotoxicity may have been attributable to their memory-enhancing effects [16]. In this study, we found that the black ginseng extract (BGE) contained 20(S)and $20(\mathrm{R})$-ginsenoside $\mathrm{Rg}_{3}$, whereas white ginseng extract (WGE) did not. Thus, BGE has potential neuroprotective and memory improvement properties. Also, note that during the heating process used to process black ginseng, protopanaxadiol-type saponins including $\mathrm{Rb}_{1}$, $\mathrm{Rg}_{1}, \mathrm{Rc}$, and $\mathrm{Rd}$ are converted to ginsenoside $\mathrm{Rg}_{3}$ by the hydrolysis of a sugar residue at C-20 or isomerization of a hydroxyl group at C-20 [17,18].

The amounts of nine ginsenosides analyzed by HPLC and the chromatograms of the ginseng extracts used in this study are presented in Table 1 and Fig. 1. The total amount of ginsenosides was $54.45 \pm 5.08 \mathrm{mg} / \mathrm{g}$ in WGE and $14.17 \pm 4.33 \mathrm{mg} / \mathrm{g}$ in BGE. WGE had a higher total ginsenoside content, but the ginsenoside $\mathrm{Rg}_{3}$ was not detected in WGE; $7.77 \pm 1.95 \mathrm{mg} / \mathrm{g}$ of the ginsenoside $\mathrm{Rg}_{3}$ was found in BGE. Ginsenoside $\mathrm{Rg}_{3}$ comprised $55 \%$ of the total ginsenoside content in black ginseng, and $25 \%$ of the ginsenoside $\mathrm{Rg}_{3}$ in the BGE was 20(S)ginsenoside $\mathrm{Rg}_{3}$. The typical difference between the saponin contents of these two ginsengs was the amount of ginsenoside $\mathrm{Rg}_{3}$ present.

\section{In vitro cholinesterase inhibition activity}

To investigate mechanisms of the memory-enhancing 
Table 1. Ginsenoside contents in ginseng extracts

\begin{tabular}{ccc}
\hline Ginsenoside $(\mathrm{mg} / \mathrm{g})$ & White ginseng extract & Black ginseng extract \\
\hline $\mathrm{Rg}_{1}$ & $7.81 \pm 4.83$ & Not detected \\
$\mathrm{Re}$ & $9.30 \pm 0.88$ & Not detected \\
$\mathrm{Rh}_{1}$ & $0.74 \pm 0.31$ & $0.67 \pm 0.15$ \\
$\mathrm{Rb}_{1}$ & $14.14 \pm 1.35$ & $2.96 \pm 1.60$ \\
$\mathrm{Rc}$ & $12.62 \pm 3.02$ & $1.61 \pm 0.71$ \\
$\mathrm{Rb}_{2}$ & $6.97 \pm 1.48$ & $0.63 \pm 0.21$ \\
$\mathrm{Rd}$ & $2.88 \pm 1.37$ & $0.53 \pm 0.44$ \\
$\mathrm{Rg}_{3}(\mathrm{R})$ & Not detected & $5.80 \pm 1.42$ \\
$\mathrm{Rg}_{3}(\mathrm{~S})$ & Not detected & $1.97 \pm 0.53$ \\
$\mathrm{Total}$ & $54.45 \pm 5.08$ & $14.17 \pm 4.33$
\end{tabular}

Values are expressed as the means $\pm \mathrm{SD}(n=3)$.
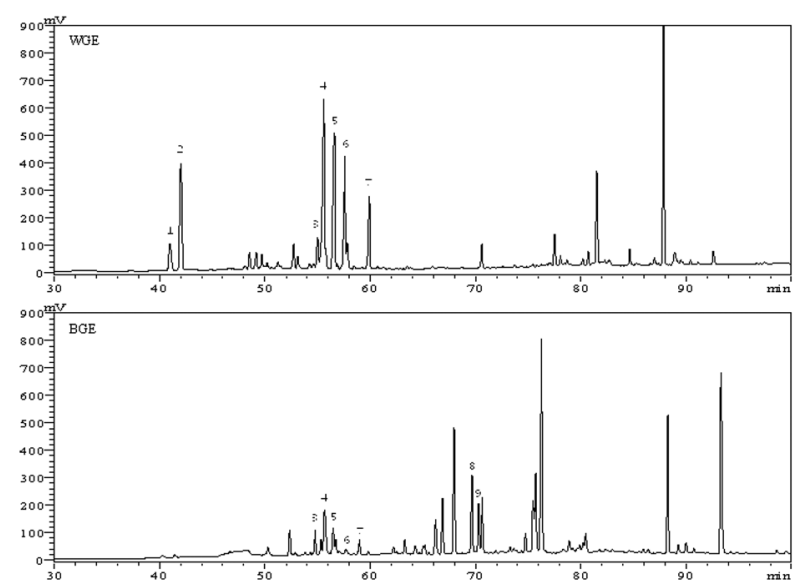

Fig. 1. HPLC-UV chromatograms of ginsenosides in ginseng extracts. Peaks: $1, \mathrm{Rg}_{1} ; 2, \mathrm{Re} ; 3, \mathrm{Rh}_{1} ; 4, \mathrm{Rb}_{1} ; 5, \mathrm{Rc} ; 6, \mathrm{Rb}_{2} ; 7, \mathrm{Rd} ; 8, \mathrm{Rg}_{3}(\mathrm{R}) ; 9$, $\mathrm{Rg}_{3}(\mathrm{~S})$. WGE, white ginseng extract; $\mathrm{BGE}$, black ginseng extract.

effects of ginseng extract, we measured the activity of cholinergic marker enzymes including AChE (Fig. 2) and $\mathrm{BChE}$ (Fig. 3). The rate of the AChE-mediated hydrolysis of acetylthiocholine was determined by measuring the rate of production of free sulfur groups produced as acetylthiocholine was hydrolyzed to thiocholine [19]. On learning and memory deficits associated with SCOP treatment model, the increased $\mathrm{AChE}$ activity produced by SCOP was significantly inhibited by WGE and BGE $(p<0.001)$ [17].

The ethanol extracts of black ginseng and white ginseng exhibited detectable $\mathrm{ChE}$ inhibitory activities against both $\mathrm{AChE}$ and $\mathrm{BChE}$, with $\mathrm{IC}_{50}$ values of $48.08 \pm 7.49 \mathrm{mg} / \mathrm{mL}$ and $66.32 \pm 3.00 \mathrm{mg} / \mathrm{mL}$, and $146.94 \pm 4.66 \mathrm{mg} / \mathrm{mL}$ and $281.75 \pm 5.29 \mathrm{mg} / \mathrm{mL}$, respectively. The $\mathrm{IC}_{50}$ for $\mathrm{AChE}$ inhibition by BGE $(48.08 \pm 7.49$ $\mathrm{mg} / \mathrm{mL}$ ) was $32.7 \%$ of that by WGE (Table 2). The $\mathrm{IC}_{50}$ for $\mathrm{BChE}$ inhibition by BGE was $23.5 \%$ of that by

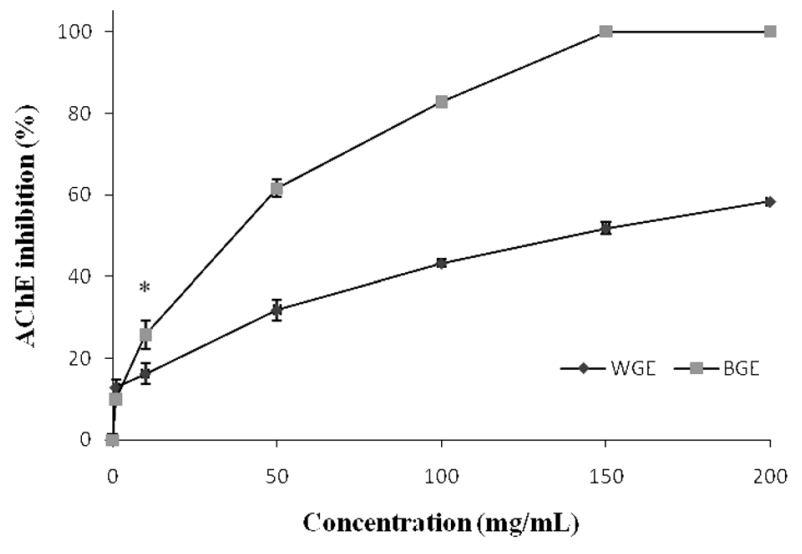

Fig. 2. Inhibitory effects of various concentrations of ginseng extracts on acetylcholinesterase (AChE) activity. Results are expressed as means $\pm S D$ from triplicate determinations. WGE, white ginseng extract; BGE, black ginseng extract. ${ }^{*} p<0.05$ vs. WGE.

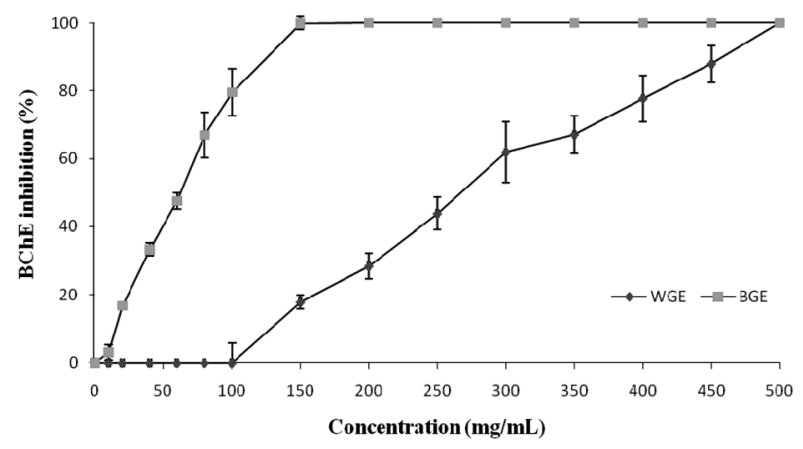

Fig. 3. Inhibitory effects of various concentrations of ginseng extracts on butyrylcholinesterase (BChE) activity. All values are expressed as means $\pm S D$ from triplicate determinations. WGE, white ginseng extract; BGE, black ginseng extract.

WGE. BGE showed more potent ChE inhibitory activity than WGE, probably due to the compositional differences between their active components. Ginseng extracts, especially BGE, inhibited ChE activity, which can lead to greater binding of $\mathrm{ACh}$ to the postsynaptic $\mathrm{ACh}$ receptor.

\section{In vitro antioxidant activity assay}

The anti-oxidative and free radical scavenging effects of ginseng and some of its selected ingredients have been investigated extensively. In the current study, both samples tested exhibited marked antioxidant activities that were attributable to the total phenolic contents $(p<0.05)$. Typical antioxidant activities of BGE and WGE are shown in Table 2, indicating that the BGE displayed stronger antioxidant activity. A typical difference in the characteristics between these two ginseng extracts is the higher ginsenoside $R b_{1} / R b_{2}$ ratio in the black gin- 
Table 2. Acetylcholinesterase (AChE) and butyrylcholinesterase (BChE) inhibitory and antioxidant activities

\begin{tabular}{|c|c|c|c|c|}
\hline & \multirow{2}{*}{$\begin{array}{l}\text { Ascorbic acid } \\
(\mathrm{mg} / \mathrm{mL})\end{array}$} & \multirow{2}{*}{$\begin{array}{l}\text { Tacrine } \\
(\mathrm{nM} / \mathrm{mL})\end{array}$} & \multicolumn{2}{|c|}{ Ginseng extracts } \\
\hline & & & $\begin{array}{l}\text { White ginseng extract } \\
\qquad(\mathrm{mg} / \mathrm{mL})\end{array}$ & $\begin{array}{l}\text { Black ginseng extract } \\
(\mathrm{mg} / \mathrm{mL})\end{array}$ \\
\hline $\operatorname{AChE}\left(\mathrm{IC}_{50}\right)$ & - & $824.70 \pm 135.21$ & $146.94 \pm 4.66$ & $48.08 \pm 7.49$ \\
\hline $\mathrm{BChE}\left(\mathrm{IC}_{50}\right)$ & - & $394.45 \pm 137.39$ & $281.75 \pm 5.29$ & $66.32 \pm 3.00$ \\
\hline Polyphenol content & - & - & $20.40 \pm 0.90$ & $34.12 \pm 0.18$ \\
\hline $\mathrm{DPPH}\left(\mathrm{SC}_{50}\right)$ & $0.11 \pm 0.14$ & - & $4.12 \pm 0.80$ & $2.28 \pm 1.33$ \\
\hline Superoxide dismutase $\left(\mathrm{IC}_{50}\right)$ & $0.77 \pm 0.11$ & - & $88.99 \pm 5.80$ & $42.23 \pm 4.16$ \\
\hline Xanthine oxidase $\left(\mathrm{IC}_{50}\right)$ & $0.48 \pm 0.38$ & - & $11.20 \pm 0.99$ & $2.41 \pm 0.17$ \\
\hline
\end{tabular}

Values are expressed as the means \pm SD $(n=3)$.

DPPH, 2,2-diphenyl-1-picryl-hydrazyl.

seng $(4.85 \pm 2.61)$ compared to that of the white ginseng

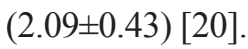

We analyzed the compositional differences in active compounds between these two kinds of ginseng. The total phenolic contents of extracts from WGE and BGE are summarized in Fig. 4. BGE, which exhibited stronger antioxidant activities than WGE, showed a higher concentration of polyphenols. BGE had a total phenolic content of $31.12 \mathrm{mg} / \mathrm{g}$, whereas that of WGE was 20.40 $\mathrm{mg} / \mathrm{g}(p<0.05)$. The phenolic compounds of ginseng have been reported to play an important role in the inhibition of aging [21,22].

The $\mathrm{SC}_{50}$ values for the DPPH radical-scavenging activities of the ginseng extracts at various concentrations are presented in Fig. 5; ascorbic acid was used as a positive control. Compared to ascorbic acid $(0.11 \pm 0.14 \mathrm{mg} /$ $\mathrm{mL})$, BGE $(2.28 \pm 1.33 \mathrm{mg} / \mathrm{mL})$ exhibited higher radicalscavenging activities than WGE $(4.12 \pm 0.80 \mathrm{mg} / \mathrm{mL})$. Nonsaponin components of Korean ginseng exhibit free radicalscavenging effects that are related to the aging of cells [23].

From studies on the autoxidation of pyrogallol, the superoxide anion radical in the reactions was investigated with the aid of SOD. SOD activity according to various concentrations of ginseng extracts is depicted in Fig. 6. In the case of BGE, the SOD activity reached $100 \%$ effect at $100 \mathrm{mg} / \mathrm{mL}$; however, with WGE, that activity was observed at $200 \mathrm{mg} / \mathrm{mL}$. From 10 to $100 \mathrm{mg} /$ $\mathrm{mL}$, BGE showed a stronger effect (average $48 \%$ ) than WGE, and BGE showed significantly higher inhibition activity $(p<0.05)$ between 50 and $100 \mathrm{mg} / \mathrm{mL}$. As a positive control, ascorbic acid was also examined for SODlike activities. $\mathrm{The} \mathrm{IC}_{50}$ values for the SOD-like activities in ascorbic acid, BGE, and WGE were $0.77 \pm 0.11$, $42.23 \pm 4.16$, and $88.99 \pm 5.80 \mathrm{mg} / \mathrm{mL}$, respectively.

$\mathrm{XO}$, which induces gout through the formation of uric acid, also causes oxidative damage to tissues in the living body through generation of the superoxide anion

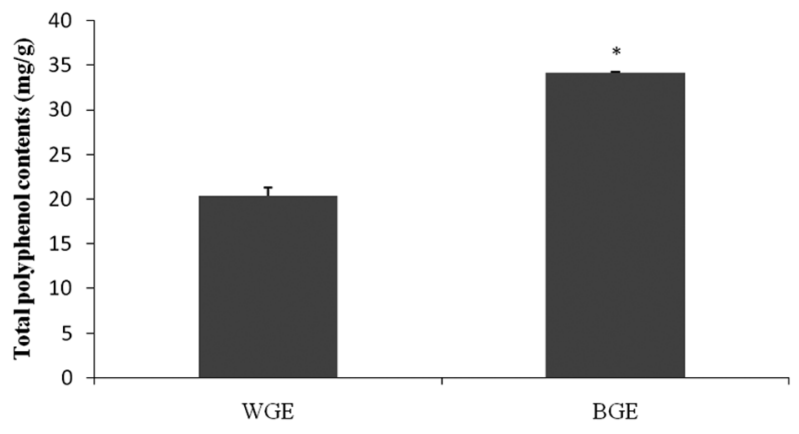

Fig. 4. Contents of polyphenol compounds in extracts from Panax ginseng C.A. Meyer. Results are expressed as means \pm SD from triplicate determinations. WGE, white ginseng extract; BGE, black ginseng extract. ${ }^{*} p<0.05$ vs. WGE.

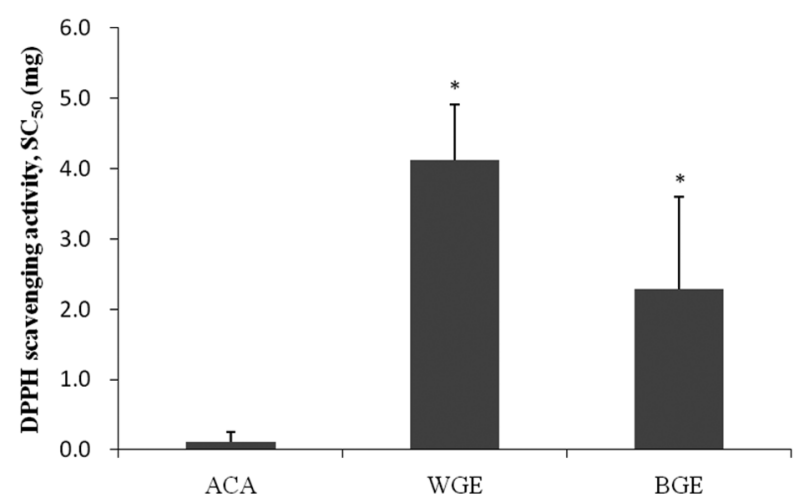

Fig. 5. $\mathrm{SC}_{50}$ values for 2,2-diphenyl-1-picryl-hydrazyl (DPPH) radical scavenging activities according to the concentration of various ginseng extracts. ACA, ascorbic acid; WGE, white ginseng extract; BGE, black ginseng extract. * $p<0.05$ vs. ACA.

radical [24]. The $\mathrm{IC}_{50}$ values for the XO inhibition activities of ginseng extracts of various concentrations are presented in Fig. 7. As a positive control, ascorbic acid was also examined for XO inhibition activities. Compared to ascorbic acid $(0.68 \mathrm{mg} / \mathrm{g})$, BGE $(2.41 \mathrm{mg} / \mathrm{g})$ showed significantly higher inhibition activity $(p<0.05)$ than WGE $(11.20 \mathrm{mg} / \mathrm{g})$. 


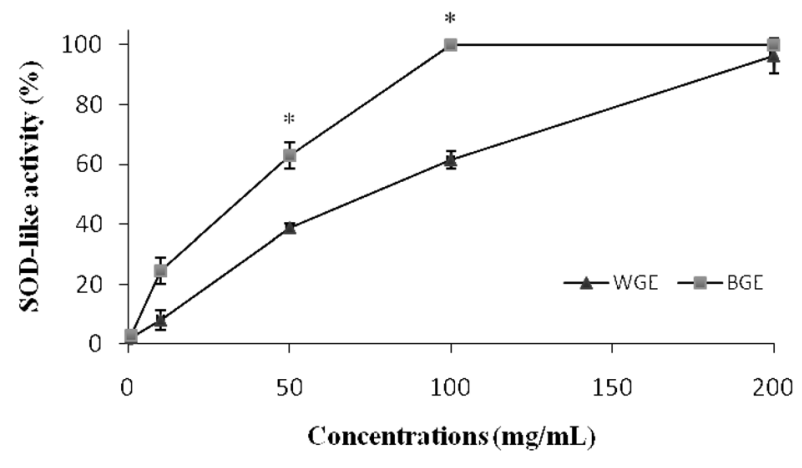

Fig. 6. Superoxide dismutase (SOD) activity according to various concentrations of ginseng extracts. Results are expressed as means $\pm S D$ from triplicate determinations. WGE, white ginseng extract; BGE, black ginseng extract. ${ }^{*} p<0.05$ vs. WGE.

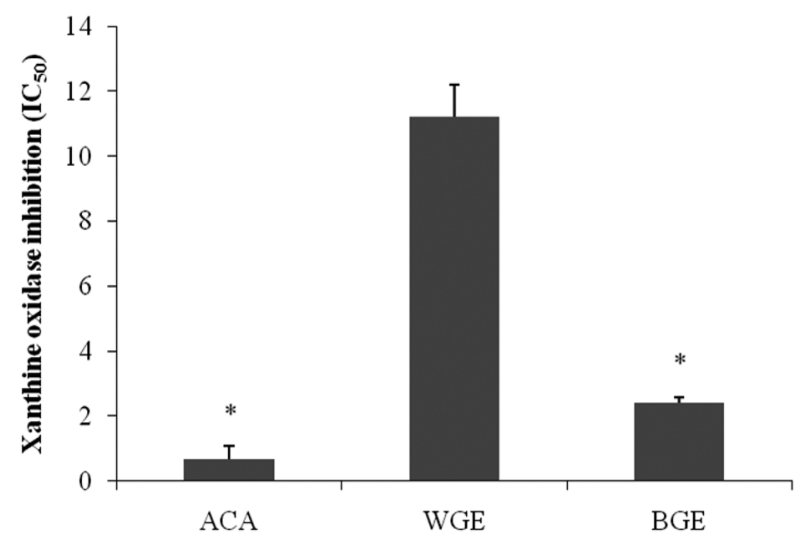

Fig. 7. $I C_{50}$ values for the inhibitory effects of different concentrations of various ginseng extracts on xanthine oxidase activity. Results are expressed as means $\pm S D$ from triplicate determinations. ACA, ascorbic acid; WGE, white ginseng extract; BGE, black ginseng extract. ${ }^{*} p<0.05$ vs. WGE.

In conclusion, the total amount of ginsenosides was higher in WGE than in $\mathrm{BGE}$, but the ginsenoside $\mathrm{Rg}_{3}$ was detected in BGE and not in WGE. The antioxidant activity of BGE was greater than that of WGE, through all of the assays, suggesting that the relationship between the total saponin content and antioxidant activity is not important. Nonetheless, ginsenoside $\mathrm{Rg}_{3}$ and nonsaponin components may be related to the antioxidant and $\mathrm{ChE}$ inhibitory activities [25,26].

\section{ACKNOWLEDGEMENTS}

This study was financially supported by research fund of Chungnam National University in 2009.

\section{REFERENCES}

1. O’Hara M, Kiefer D, Farrell K, Kemper K. A review of 12 commonly used medicinal herbs. Arch Fam Med 1998;7:523-536.

2. Lee HJ, Shen GN, Kim EK, Shin HJ, Myung CS, Oh HJ, Kim DH, Roh SS, Cho W, Seo YB, et al. Preparation of black ginseng and its antitumor activity. Korean J Orient Physiol Pathol 2006;20:951-956.

3. Han BH, Park MH, Woo LK, Woo WS, Han YN. Studies on the antioxidant components of Korean ginseng (I). Korean Biochem J 1979;12:33-40.

4. Han BH, Park MH, Han YN. Studies on the antioxidant components of Korean ginseng (III). Arch Pharm Res 1981;4:53-58.

5. Wee JJ, Park JD, Kim MW, Lee HJ. Identification of phenolic antioxidant components isolated from Panax ginseng. J Korean Agric Chem Soc 1989;32:50-56

6. Wee JJ, Shin JY, Kim SK, Kim MW. Comparison of phenolic components between Korean and American ginsengs by thin-layer chromatography. J Ginseng Res 1998;22:91-95.

7. Ballard CG, Greig NH, Guillozet-Bongaarts AL, Enz A, Darvesh S. Cholinesterases: roles in the brain during health and disease. Curr Alzheimer Res 2005;2:307-318.

8. Becker RE, Moriearty P, Unni L, Vicari S. Cholinesterase inhibitors as therapy in Alzheimer's disease: benefit to risk considerations in clinical application. In: Becker RE, Giacobini E, eds. Alzheimer's disease: from molecular biology to therapy. Boston: Birkhäuser, 1997. p.257-266.

9. Shi W, Wang Y, Li J, Zhang H, Ding L. Investigation of ginsenosides in different parts and ages of Panax ginseng. Food Chem 2007;102:664-668.

10. Ellman GL, Courtney KD, Andres V Jr, Feather-Stone RM. A new and rapid colorimetric determination of acetylcholinesterase activity. Biochem Pharmacol 1961;7:8895.

11. Folin O, Denis W. On phosphotungstic-phosphomolybdic compounds as color reagents. J Biol Chem 1912;12:239243.

12. Blois MS. Antioxidant determinations by the use of a stable free radical. Nature 1958;181:1199-1202.

13. Marklund S, Marklund G. Involvement of the superoxide anion radical in the autoxidation of pyrogallol and a convenient assay for superoxide dismutase. Eur J Biochem 1974;47:469-474.

14. Stirpe F, Corte ED. The regulation of rat liver xanthine oxidase. J Biol Chem 1969;244:3855-3861.

15. Tian J, Fu F, Geng M, Jiang Y, Yang J, Jiang W, Wang C, Liu K. Neuroprotective effect of 20(S)-ginsenoside $\mathrm{Rg}_{3}$ on cerebral ischemia in rats. Neurosci Lett 2005;374:9297.

16. Bao HY, Zhang J, Yeo SJ, Myung CS, Kim HM, Kim JM, 
Park JH, Cho J, Kang JS. Memory enhancing and neuroprotective effects of selected ginsenosides. Arch Pharm Res 2005;28:335-342.

17. Lee MR, Yun BS, Liu L, Zhang DL, Wang Z, Wang CL, Gu LJ, Wang CY, Mo EK, Sung CK. Effect of black ginseng on memory improvement in the amnesic mice induced by scopolamine. J Ginseng Res 2010;34:5158.18. Han BH, Park MH, Han YN, Woo LK, Sankawa U, Yahara S, Tanaka O. Degradation of Ginseng Saponins under Mild Acidic Conditions. Planta Med 1982;44:146149.

19. Yoon NY, Chung HY, Kim HR, Choi JS. Acetyl- and butyrylcholinesterase inhibitory activities of sterols and phlorotannins from Ecklonia stolonifera. Fish Sci 2008; 74:200-207.

20. $\mathrm{Hu} \mathrm{C}$, Kitts DD. Free radical scavenging capacity as related to antioxidant activity and ginsenoside composition of Asian and North American ginseng extracts. J Am Oil Chem Soc 2001;78:249-255.

21. Choi CS, Kim KI, Hong HD, Choi SY, Lee YC, Kim KT,
Rho J, Kim SS, Kim YC. Phenolic acid composition and antioxidative activity of white ginseng (Panax ginseng, C. A. Meyer). J Ginseng Res 2006;30:22-30.

22. Kong YH, Lee YC, Choi SY. Neuroprotective and antiinflammatory effects of phenolic compounds in Panax ginseng C. A. Meyer. J Ginseng Res 2009;33:111-114.

23. Oh JH, Kim EH, Kim JL, Moon YI, Kang YH, Kang JS. Study on antioxidant potency of green tea by DPPH method. J Korean Soc Food Sci Nutr 2004;33:1079-1084.

24. Hatano T, Yasuhara T, Fukuda T, Noro T, Okuda T. Phenolic constituents of licorice. II. Structures of licopyranocoumarin, licoarylcoumarin and glisoflavone, and inhibitory effects of licorice phenolics on xanthine oxidase. Chem Pharm Bull (Tokyo) 1989;37:3005-3009.

25. Khachaturian ZS. Diagnosis of Alzheimer's disease. Arch Neurol 1985;42:1097-1105.

26. Giacobini E. Cholinesterase inhibitors do more than inhibit cholinesterase. In: Becker RE, Giacobini E, eds. Alzheimer's disease: from molecular biology to therapy. Boston: Birkhäuser, 1997. p.188-204. 